\title{
A sombra de um corpo que se anuncia: corpo, imagem e envelhecimento*1
}

\author{
Junia de Vilhena*2 \\ Joana de Vilhena Novaes*3 \\ Carlos Mendes Rosa*4
}

\begin{abstract}
A velhice tem várias facetas e preconceitos associados ao que representa. Nosso objetivo é refletir acerca das peculiaridades relacionadas ao fenomeno ser velho e seus impactos no sujeito, destacando o lidar com o desencontro entre o inconsciente atemporal e o corpo envelhecido, chamado de envelhescência. Partimos do pressuposto que os discursos que normatizam o corpo tomam conta da vida simbólico-subjetiva do sujeito, não deixando espaço para a construção de uma narrativa individual.
\end{abstract}

Palavras-chave: Envelhecimento, corpo, morte, psicanálise

*1 Trabalho apresentado no III Congresso Internacional de Gerontologia Social realizado em Coimbra, maio de 2013. Pesquisa que vem sendo desenvolvida no Laboratório Interdisciplinar de Pesquisa e Intervenção Social, LIPIS-PUC/Rio, em conjunto com a Universidade de Coimbra.

${ }^{* 2}$ Pontifícia Universidade Católica do Rio de Janeiro - PUC-Rio (Rio de Janeiro, RJ, Br).

${ }^{* 3}$ Pontifícia Universidade Católica do Rio de Janeiro - PUC-Rio (Rio de Janeiro, RJ, Br) e Universidade Veiga de Almeida (Rio de Janeiro, RJ, Br).

${ }^{*}$ IBMR Centro Universitário (Rio de Janeiro, RJ, Br). 
Reduzidos a um único tempo verbal, o pretérito, com suspeito presente e um futuro que ninguém quer.

Eliane Brum

\section{Introdução}

Não deve ter escapado ao leitor os inúmeros vocábulos que veem substituindo o termo velho: idoso, maduro, terceira idade e, finalmente, melhor idade. Por quê? Porque na sociedade ocidental capitalista ninguém quer ser velho. Ser velho é sinônimo de incapacidade física e intelectual, dependência, decadência física, psíquica e por aí vai. Criam-se então novas palavras, conceitos de idoso, terceira idade, como se fosse possível classificar os seres humanos por faixa etária como classificamos, perversamente, os países segundo seu grau de desenvolvimento e pobreza. Primeiro mundo, terceiro mundo... É neste que está a velhice ou a terceira idade.

A velhice tem um tempo, um nome, um status, várias facetas e muito preconceito associado a tudo que a ela se relaciona. Nosso objetivo é refletir criticamente acerca destas peculiaridades relacionadas ao fenômeno "ser velho" e seus impactos no sujeito. Os eufemismos que mascaram a relação automática entre envelhecimento e envilecimento no imaginário social partilhado, a drástica mudança na relação do sujeito velho com o tempo e as demais construções culturais associadas, agenciam subjetividades e incidem sobre o nosso fazer clínico.

A terceira idade é o terceiro mundo da política ou da vida. É um peso morto gestionário, socialmente marginal, cujos custos, quando não estão alimentando a indústria do turismo para $3^{\mathrm{a}}$ idade, dos cosméticos ou do body fitness, representam um "peso" muito grande na balança de pagamentos da previdência.

Quanto mais se vive biologicamente neste modelo societário, menor é o reconhecimento simbólico. Talvez, por isto, cada vez mais aumentem os investimentos naquilo que alguns sociólogos chamam de adultescência -, a eterna busca pela aparência jovem, seja no corpo, seja nas roupas, seja no estilo de vida. Como se o velho só pudesse existir socialmente sob a roupagem de uma juvenilidade mercadológica. 


\section{ENSAIO}

Contudo, a juvenilidade não pode ser confundida com jovialidade. A primeira é biológica enquanto a segunda é existencial e simbólica. Jovialidade é um nome que inscreve uma condição divina - vem de Júpiter -, no latim jovis. Outro nome para alegria, para a aceitação da vida tal qual ela nos aparece, como uma nuance da morte. $\mathrm{Na}$ alegria da jovialidade moço e velho se reencontram, trocam e podem sentir a mesma saudade que em vida se sente da vida, de partes nossas, saudades das partes corporais, de partes espirituais, que morrem ao longo da existência.

A antropologia cultural e social moderna (Geertz, 1996) nos diz que a velhice não deve ser considerada apenas em seus aspectos físicos e cronológicos, mas sim como uma representação social. E por que não simbólica também? Destaquemos a memória, entendida como um fenômeno social, e suponhamos que a tarefa de lembrar ou relembrar seja tanto ou mais frutífera quanto maior for sua relevância e inserção na sociedade e no contexto histórico-cultural. São as lembranças dos velhos, em nossa cultura, relevantes ou positivamente qualificadas?

Na cultura ocidental moderna o velho nada tem mais a dizer que não seja no plano biológico. Ele é o infans. E não tem, porque lhe falta a autoridade. Não existe mais entre nós a cultura da ancestralidade ainda presente em algumas comunidades litúrgicas de afrodescendentes (a figura do Egum) ou mesmo em culturas orientais. Ainda que, até nesta última, o lugar simbólico do ancião também está sendo demolido.

A autoridade decorre de uma forte presença simbólica em torno da qual giram os eixos e valores éticos de um grupo. Neste modelo os anos vividos transformam-se em experiência e o velho é alguém pleno de valor. Há aí uma inclusão social, uma inclusão simbólica da morte e, como sabemos, só a inclusão da morte na vida e no espaço social garantirá uma aliança entre vivos e mortos. Daí decorre a autoridade do velho. O morto (estar velho é estar perto da morte) vai ser ancestral.

E o que é o ancestral se não alguém que vai ser a voz da fundação que cada um dos vivos, dos filhos, vai carregar para continuar mantendo os laços sociais de um grupo. Como aponta Moniz Sodré, cada grupo carrega, de certo modo narcisicamente, a voz de sua fundação (comunicação pessoal).

Disso, aliás, já nos falava Freud em diferentes formas como veremos a seguir.

Isto significa que a morte integra o ciclo social das trocas simbólicas. Em um livro, A troca simbólica e a morte, Baudrillard (1997) diz que é no século XVI que essa figura moderna da morte se generaliza, porque antes a morte era festejada. Ao observarmos as imagens da Idade Média vemos dançando o rei, a corte, o guerreiro e a morte, representada pelo esqueleto dançando junto com as pessoas.

No entanto, parece que teremos de lutar por esse direito de ficar velho em paz. De exercer as prerrogativas da velhice e não nos preocuparmos... De lidar com o desencontro entre o inconsciente atemporal e o corpo, âmbito da temporalidade, ou por um encontro da alma sem idade com o corpo que envelhece, como aponta Berlinck (2000) ao cunhar o termo envelhescência. 


\section{Pensando psicanaliticamente a velhice}

Freud caminhava com um jovem poeta e ouvia suas lamentações acerca da transitoriedade da beleza neste mundo, onde, segundo este, tudo que é belo terá seu fim um dia. A partir deste diálogo escreve um texto, quase poético, estendendo as reflexões sobre o tema da transitoriedade para outros aspectos da vida humana.

Pensar a velhice hoje, além das reflexões necessárias de caráter político, como a mudança de perspectiva do cuidado ao velho que passou da esfera privada para a esfera pública, e a exclusão social decorrente das diferentes faixas etárias, e as de ordem subjetiva, como as construções ou representações sociais que tendem a homogeneizar essa população, parece suscitar a questão do que é transitório.

Se antes falávamos da velhice em termos apenas de perdas cognitivas e executivas, hoje comemoramos entusiasmados as conquistas da medicina e os avanços legais e sociais de alguns países na defesa dos direitos dos velhos.

Atualmente um dos principais ritos de passagem que anunciava a chegada da terceira idade, a perda da libido, está perdendo autoridade. A libido, seja por uma maior liberalização dos costumes, seja por progressos da medicina, reclama seus direitos na terceira idade. Esmaece a fronteira entre as fases da vida. Envelhecer como sinônimo de decadência deixou de ser uma profecia autorrealizadora.

Mas sabemos que tal como a bela paisagem contemplada pelo amigo de Freud, quando sobrevier o inverno da alma, estas maravilhas, estes avanços, rapidamente serão solapados pela inexorabilidade do processo vital.

Freud (1914/2000) afirmava que em alguns casos de doença orgânica a libido direcionada para o mundo externo regride ao eu como suporte à condição sofrente. A famosa assertiva de Wilhelm Buck de que toda alma se encontra aprisionada na estreita cavidade do molar (no caso da dor de dente) foi magistralmente utilizada por Freud para ilustrar esse fenômeno.

Gabbay (1999) retoma o pensamento de Ferenczi (1926) acerca deste texto freudiano para afirmar que, também nos casos de envelhecimento, esse desinvestimento libidinal é algo recorrente e pode ser explicado pela mesma lógica do narcisismo. Uma vez que a libido agora se encontra escassa e o sujeito necessita de um mínimo de investimento narcísico para sobreviver, ele retira parte, ou toda libido do mundo externo nos casos mais graves, e passa a se interessar cada vez mais por suas memórias, suas fantasias e suas próprias dores, que usualmente são várias e frequentes.

Segundo a autora, alguns fenômenos típicos dessa fase, como o retraimento de interesses, certo egoísmo e a despreocupação com os fenômenos ao seu redor são confirmações desse remanejamento libidinal para o próprio eu (Gabbay, 1999). Importante frisar que estas não são características dominantes em todas as pessoas de idade avançada. 


\section{ENSAIO}

Observando a nova organização libidinal da velhice, que tanto se assemelha a primeira de nossas vidas, aquela do narcisismo primário, podemos pensar que os ciclos de desenvolvimento são realmente transitórios e se sucedem. Podemos aventar ainda a possibilidade de estes serem também partes de uma espécie de sistema fechado, onde a última fase do desenvolvimento acena com o reinício da primeira.

Evidente que se pode aplicar o conceito de transitório a todas as coisas e todos os momentos de uma existência. Simples é analisar a transitoriedade da fase infantil ou adolescente, de sorte que outras mais acenam como futuro imediato e automático. No entanto, parece difícil ficar impassível a esse questionamento sobre a finitude da existência, quando ela se aproxima cada vez mais das nossas vistas.

Se a chamada morte social já se anuncia, outros anúncios tão ou mais evidentes sensibilizam o velho nessa nova fase da vida. Quando uma mulher idosa se olha no espelho, o que este lhe devolve é uma imagem ligada a uma deterioração, uma imagem com a qual ela não se identifica. Existe uma discrepância entre a imagem inconsciente do corpo e a imagem refletida, posto que se trata de um sujeito psíquico em constante crescimento e evolução, altamente afetado pela representação de um corpo que se deteriora e pela consciência da finitude (Goldfarb, 1998).

O corpo adoecido, macilento e desvitalizado dos estágios finais da vida é criado imaginariamente pelo sujeito, muitas vezes, antes mesmo de possuí-lo verdadeiramente. Neste sentido, podemos pensar em um retorno ao estágio do espelho lacaniano, quando a criança constrói seu corpo ideal através da imagem especular do alter (Gabbay, 1999). No entanto, a nova construção não aponta para um corpo belo e idealizado para a vida, mas um corpo decrépito e adequado para a morte (Messy, 1992).

O corpo, na velhice, é o lugar privilegiado de desilusão narcísica, prometido à decadência e à morte e palco do adoecer, empurrando o sujeito a enfrentar o desafio de manter a aposta na vida. Embora o narcisismo não se afigure como uma defesa contra a pulsão de morte, o papel da ilusão para lidar com as "asperezas da vida" é inegável.

Freud (1915/2000) já nos avisara que a exigência de imortalidade, por ser tão obviamente um produto dos nossos desejos, não pode reivindicar seu direito à realidade. Todos nós padecemos do medo da perda dos nossos objetos de investimento afetivo. $\mathrm{E}$ a vida em si é alimentada por um constante gerenciamento das nossas porções de afeto, interesse, amor e tempo - sim, o tempo se tornou um capital na economia moderna.

As consequências mais comuns no ser humano do "medo de perder algo valioso" são a antecipação defensiva e a culpa. Sempre que estamos excessivamente felizes ou em momentos importantes de nossa existência, esses mecanismos entram em ação nos informando que a felicidade ou estabilidade a qual nos encontramos pode acabar subitamente; são transitórios.

A perda relaciona-se em última análise com o receio da morte. Ou seja, a perda da existência. O homem primitivo aprendeu a admitir a morte como fato inalterável, mas não consegue assimilar a sua própria aniquilação. Por essa razão a nossa história 
guarda uma profusão de mitos e religiões espiritualistas. Nada do pulsional solicita a crença da própria morte (Freud, 1915).

Como aponta Ariès (2003), a morte é um tabu na sociedade moderna e hoje, com as novas e avançadas tecnologias para o corpo, com técnicas para o prolongamento da vida que por sua vez trazem a discussão médica e ética sobre o controle técnico do momento da morte, verificamos que fica cada vez mais complexo lidar com a velhice e com seus imperativos que são, apesar de todos os avanços da ciência, a aproximação com a morte e a decadência física.

Freud (1917/2000) nos ajuda a compreender esse horror à morte, na vertente clínica, ao afirmar que o inconsciente não possui representação alguma do que seria morrer, ou deixar de existir. A ideia da morte remonta às angústias impossíveis de significar que o bebê experimenta nos primeiros meses do seu desenvolvimento. $\mathrm{O}$ autor toca no tema também em sua análise das sociedades, ao mostrar que um dos maiores medos do ser humano é ver o seu próprio corpo definhar e lhe trazer a infelicidade e o sofrimento.

A infelicidade humana, segundo Freud (1930/2000), pode advir dos relacionamentos que terminam e deixam um vazio na vida do sujeito, do mundo que apresenta desafios gigantescos para a frágil constituição humana e principalmente do próprio corpo que se encaminha inexoravelmente para a morte. Freud aponta o corpo como uma das fontes do mal-estar humano, sublinhando que "este permanecerá para sempre como uma estrutura passageira, com limitada capacidade de adaptação e realização", mas que este reconhecimento não deveria ter um efeito paralisador na medida em que podemos mitigar este sofrimento, em parte (inclusive com o avanço da ciência), mas nunca totalmente (1930, p. 85).

Para Berlinck (2000) a envelhescência pode ser definida - enquanto objeto e circunstância psíquica - como um desencontro entre o inconsciente atemporal e o corpo, âmbito da temporalidade, ou por um encontro da alma sem idade com o corpo que envelhece, como apontamos anteriormente. Esse encontro-desencontro constitui uma discrepância com efeitos traumáticos cuja complexidade situa-se no arranjo entre o corpo, a subjetividade e o social, justamente na intersecção desses campos, aprisionando o sujeito por seu corpo, sua estrutura psíquica e por seu lugar no social que é assimilado e atuado pelo velho. Essa crise traumática exige um trabalho psíquico: a envelhescência.

\section{Tempo para envelhecer}

$\mathrm{Na}$ "moderna pedagogia" de atividades para a terceira idade criam-se atividades exclusivas para os velhos que vão da universidade às academias de dança, deixando 


\section{ENSAIO}

de lado o fato de que o que vai enriquecer-lhes a vida é exatamente o contato com os mais jovens, os novos amigos, o fazer e trocar experiências distintas. Em seu livro Filosofia do espírito científico Bachelard (1972) aponta a importância do "velho" conhecimento na formulação dos novos. O que significa dizer que a experiência do vivido e dos antigos saberes não pode e não deve ser desprezada. Sem o velho conhecimento não se cria o novo.

Quando falamos do tempo cronológico, ao qual nos referimos como transitório e fugidio, esquecemo-nos do chamado tempo vivencial, que algumas culturas chamam de kairós. Um tempo que se refere à fruição das coisas e pode ser maior ou menor de acordo com o gerenciamento subjetivo que fazemos dele. Tanto na infância quanto na velhice temos um tempo outro para a realização das tarefas diárias. A vida pode ser experienciada sem as exigências sociais da modernidade que quer pressa para tudo.

Aproveitar esse distanciamento que a velhice traz em relação ao cotidiano e suas pressões deve ser algo valioso para os velhos, e não pode ser tido como sinônimo de incapacidade e signo de exclusão.

É sabido que a sociedade moderna tende a tratar os velhos com desprezo, devido ao declínio em suas forças e capacidades. No entanto, essa marginalização do velho não parece ocorrer em todas as culturas. Segundo Gebran (1999) as "sociedades ágrafas" valorizam e reverenciam o saber e o fazer daqueles que já acumularam experiência pelos muitos anos vividos permitindo, assim, a continuidade da cultura. Nestas sociedades a única maneira de se adquirir o saber, na ausência de qualquer representação escrita (livros, jornais, computadores etc.), é perguntando e escutando o que os mais velhos têm para ensinar.

Para nós do campo psi, perguntar implica questionar e ouvir o que todos têm a dizer: homens ou mulheres, pobres ou ricos, jovens ou velhos. Pensando nestes últimos assinalamos a importância do reconhecimento de histórias de toda uma vida repleta de feitos épicos, trágicos, cômicos em suas múltiplas experiências subjetivas. Diferentes nuances e expressões do pathos (paixão e padecimento) que os guiou ao longo de suas existências. Lembremo-nos que pathos não é apenas sofrimento, mas tudo aquilo que nos constitui, o que nos dá a forma que temos e que nos constitui como sujeitos.

Mais ainda, todos nós psicanalistas reconhecemos em nosso Egum (Freud) o lugar da ancestralidade, de transmissor de um saber que nos foi legado e sobre o qual construímos a nossa existência enquanto profissionais.

\section{Tentando escutar}

Dentro de poucas décadas o número de mortes voltará a superar o de nascimentos em vários países, inclusive o Brasil. E não será por conta dos motivos passados, guerras 
ou epidemias, mas pela conjugação da mudança de comportamento, que caminha para a redução da natalidade a menos de um filho por mulher, e pelo avanço da medicina, proporcionando longevidade crescente à população dos países desenvolvidos.

Desta maneira, fica muito difícil definir nos dias de hoje quando começa realmente a chamada terceira idade. Uma parte da população do mundo trabalha até perder as forças ou adoecer. Outra se aposenta ainda no vigor das forças chegando, algumas vezes, a adoecer de tédio; amargurados com tudo, infelizes e desapontados com o que julgavam ser um direito de descansar e viver bem (Vilhena, Rosa \& Novaes, 2013).

Servindo-nos do ideário vigente, que afirma a velhice como tempos do descanso, de poucas emoções, do corpo em decadência e, nos tempos atuais, das vidas descartáveis, vale ressaltar que é o olhar que a vê como estrangeira, que a torna mais estranha em seus próprios corpos. É este olhar que cria os interditos que balizam o que supostamente é ou deixa de ser adequado a uma faixa etária. O olhar alheio é, não raro, mais cruel que a decadência das formas (Vilhena \& Novaes, 2009).

A ciência e suas fantásticas descobertas no ramo farmacêutico proveem pílulas de longevidade capazes de "tratar" a velhice, como se algo natural precisasse de tratamento. O mercado da indústria anti-aging movimenta hoje US\$ 100 bilhões ao ano, e em 1990 esse setor nem sequer existia na economia mundial (Cabral, 2012).

Para os desconfortos do envelhecimento, a reposição hormonal. Para os sinais da passagem do tempo, as cirurgias e a cosmetologia. A menopausa, vista como algo "natural" é reduzida ao âmbito biológico, com seus sintomas "desagradáveis", facilmente suprimíveis com o tratamento adequado. Para os homens, simplesmente Viagra.

Contudo, acreditamos que o corpo solicita outro discurso que não se restringe às reposições hormonais ou às disfunções eréteis. $\mathrm{O}$ que nos parece fundamental em relação ao conceito de saúde, especialmente se tomamos como referência a noção de Sawaia (2006) que coloca a saúde como um princípio ético, é que os profissionais do cuidado não dão relevância aos aspectos psicológicos e emocionais do envelhecimento.

Como aponta Gromann (2007) há um silêncio imposto aos órgãos em sua significação mais profunda - como se estivéssemos diante de um corpo sem narrativa. $\mathrm{O}$ enfermo como subjetividade foi sendo progressivamente excluído e silenciado da cena da enfermidade. Excluído que foi de qualquer implicação no processo de adoecimento. O que observamos é o total descolamento do sujeito com relação ao sintoma que lhe anuncia e deveria representá-lo. O corpo, tratado apenas como organismo; corpo da ordem da natureza, do qual a medicina se ocupa com grande maestria.

O desejo e o gozo, dois baluartes da concepção do sujeito, estão excluídos do corpo homeostático da clínica médica; neste corpo só se observam dores e afecções com o intuito corretivo e normalizador. Quando deveria ser o inverso, pois o corpo é um lugar de gozo. E o sintoma vem expor uma falta. É nesse momento que deveríamos nos perguntar a respeito do desejo do Outro, "por que" ou "o que ele quer de mim"? 


\section{ENSAIO}

Longe de promover um desaparecimento da angústia, trata-se de tornar possível a resolução de um tipo de angústia paralisante e caminhar em direção a outras angústias vivenciais. $\mathrm{O}$ fundamental nesse contexto é a mudança na relação do sujeito com o mundo que o cerca, restabelecendo os nexos psicológicos, fisiológicos e sociais, e eliminando a separação entre pensar, sentir e agir. Saúde é liberdade de movimentos do corpo e da mente, é possibilidade de ter esperanças e potencializá-las na ação.

É esta dimensão que fica perdida quando reduzimos os cuidados com o corpo senil (ou qualquer outro!) a questões como vaidade ou funcionalidade, deixando de lado todos os aspectos subjetivos envolvidos no processo de envelhecimento. É como se desistíssemos do desafio de significar seus corpos de forma diferenciada daquela em que foram pensados até muito recentemente.

Se por um lado a cultura impõe de forma radical uma estética onde não há lugar para a velhice e um desempenho que é incompatível com o envelhecer, é preciso estar atento àquilo que retira do sujeito a sua implicação em seu sintoma, em seu pathos, que dificilmente será transformado em questão, posto que será reduzido a uma intervenção cirúrgica, uma medicação adequada, um tratamento rejuvenescedor ou a internação em um asilo.

Da mesma maneira que uma imagem não se reduz a uma etapa, não podemos reduzir o envelhecimento à velhice. O envelhecimento é um processo irreversível, que se inscreve no tempo. Começa com o nascimento e progride inexoravelmente até a destruição do indivíduo (Messy, 1992).

Partimos do pressuposto que os ciclos biológicos seriam momentos em que haveria uma rearticulação das marcas sensoriais, constitutivas das imagens corporais (Dolto, 1984; Dolto \& Nasio, 1991) que servem de base para o eu. Nesse momento, o corpo portaria sensações que poderiam permitir pensar sua condição de forma muito distinta, desde que narrativas possam ser construídas.

\section{Considerações finais}

Nos dias de hoje, não podemos sustentar que a subjetividade se processe de forma tão desgastante, a ponto de produzir rigidez e imutabilidade, exaurindo o movimento pulsional (Millot, 1988). Os sujeitos contemporâneos se constituem num universo caracterizado pela aceleração de mudanças que não mais asseguram uma estabilidade identitária (Kristeva, 1993). O próprio Freud, desde a segunda tópica, demarcou o caráter inesgotável da insistência pulsional, e é disso que tratamos quando nos dedicamos a desvelar os labirintos do desejo humano, que se apresenta encarnado num corpo sexuado. 
A velhice deve ser considerada como um fenômeno biológico com profundas consequências psicológicas. Exatamente por ter uma dimensão existencial que modifica a relação da pessoa com o tempo, o mundo e com sua própria história. Disso já nos falava Freud que aos setenta anos e em luta com sua prótese no maxilar, que lhe consumia uma "energia preciosa", dizia ainda preferir a existência à extinção.

É fundamental frisar também que "velhice" não é diagnóstico. Muito menos insígnia clínica que demande qualquer intervenção psicanalítica. Também é verdade que não existe a necessidade real de se ter um "problema" para que exista demanda de análise. Que o diga uma paciente nossa, quando afirma que "análise não é algo que a gente precisa, é algo que a gente merece".

$\mathrm{O}$ efeito do discurso vigente - modulado pela lógica social do tempo útil que objetos, utensílios eletrônicos e pessoas devem ter, como se tudo tivesse um prazo de validade mais curto na sociedade moderna — tem profundo impacto na economia psíquica dos pacientes velhos, ao ponto dos mesmos afirmarem estar sofrendo de velhice. O termo velhice assume valor de significante, redefinindo a forma de o sujeito conceber a si mesmo e ao seu próprio sofrimento.

Em psicanálise acredita-se que o sujeito se apropria de sua doença sempre de forma peculiar, e só a análise da narrativa particular daquele sujeito é capaz de deslindar os meandros de seu sintoma. Em tempos de patologização da normalidade, o fenômeno biológico do amadurecimento ganha status de doença e promove efeitos sintomáticos particularizados nos velhos. Daí a necessidade, mais uma vez, de se colocar em palavras estes efeitos com o objetivo de desconstruir ou reelaborar as angústias e dores advindas da condição de estar velho.

A profusão de enunciados pedagógicos, no campo das práticas, que objetivariam uma melhor adaptação às chamadas perdas da velhice, acabam por ressaltá-las. Aprisionado em categorias e em ideais, retira-se do sujeito sua singularidade tornando seu caminho uma estrada de mão única, onde o desejo não mais comparece. Aos velhos doentes, cansados, em sofrimento, a diferença é calada e reduzida à explanação: “é da velhice", ou "são os desconfortos da melhor idade...".

A singularidade da dor (física ou psíquica) como experiência subjetiva, torna-a um campo privilegiado para pensarmos a relação entre o indivíduo e a sociedade. Toda experiência individual inscreve-se num campo de significações coletivamente elaborado; se até isto lhe é negado o que dizer desta existência?

Como resposta a esta e muitas outras questões que o texto levanta, propusemo-nos a falar da velhice naquilo que ela tem de mais precioso, ou seja, a oportunidade de existir, ainda que caracterizada como estágio final desta mesma existência. Daí termos resgatado o conceito de envelhescência; mais do que um puro significante, a envelhescência é um ato de subjetivação (Berlinck, 2000).

Em um mundo cada vez mais complexo, onde a economia de trocas simbólicas, apoiada nas novas tecnologias, esmaece o conceito de fronteiras e territórios 
(Turkle, 1985), também os suportes identitários se transformam. Temos de repensar os limites do corpo e da anatomia na constituição das subjetividades, situando a velhice em meio a esta revolução, que inflete significativamente sobre os saberes médico e psicológico.

\section{Referências}

Ariès, P. (2003). História da morte no Ocidente. Rio de Janeiro: Ediouro.

Bachelard, G. (1972). Filosofia do novo espírito científico. Lisboa: Ed. Presença.

Baudrillard, J. (1997). A troca simbólica e a morte. São Paulo: Loyola.

Berlinck, M. T. (2000). Psicopatologia Fundamental. São Paulo: Escuta.

Cabral, M. (2012). Ganhos e perdas. Rev. Página 22, Ed. 70. Recuperado em 20 abril de $2013 \mathrm{de}<\mathrm{http} / /$ pagina22.com.br/index.php/2012/12/ganhas-e-perdas/>.

Dolto, F. (1984). Sexualidade feminina. Libido, erotismo, frigidez. São Paulo: Martins Fontes.

Dolto, F. \& Nasio, J. D. (1991). A criança do espelho. Porto Alegre: Artes Médicas.

Ferenczi, S. (1926). Contraindicações da técnica ativa. In Obras completas III. São Paulo: Martins Fontes.

Freud, S. (2000). Sobre o narcisismo: uma introdução. In Edição Eletrônica Brasileira das Obras Psicológicas Completas de Sigmund Freud (Vol. 14). Rio de Janeiro: Imago. (Trabalho original publicado em 1914).

Freud, S. (2000). Sobre a transitoriedade. In Edição Eletrônica Brasileira das Obras Psicológicas Completas de Sigmund Freud (Vol. 14). Rio de Janeiro: Imago. (Trabalho original publicado em 1915).

Freud, S. (2000). Luto e melancolia. In Edição Eletrônica Brasileira das Obras Psicológicas Completas de Sigmund Freud (Vol. 14). Rio de Janeiro: Imago. (Trabalho original publicado em 1917).

Freud, S. (2000). O mal-estar na civilização. In Edição Eletrônica Brasileira das Obras Psicológicas Completas de Sigmund Freud (Vol. 21). Rio de Janeiro: Imago. (Trabalho original publicado em 1930).

Gabbay, R. (1999). Considerações sobre psicanálise com idosos. Anais da Primeira Jornada de Psicanálise com Idosos e suas Interseções, Rio de Janeiro: EBP, 31-39.

Gebran, P. (1999). Velhos nas sociedades ágrafas. Anais da Primeira Jornada de Psicanálise com Idosos e suas Interseções, Rio de Janeiro: EBP, 20-30.

Geertz, C. (1996). Representações simbólicas. Rio de Janeiro: Zahar.

Goldfarb, D. C. (1998). Corpo, tempo e envelhecimento. São Paulo: Casa do Psicólogo.

Gromann, R. M. G. (2007, jun.). A política do erotismo na maturidade feminina: um estudo sobre as relações entre os estados hipocondríacos e melancólicos. Revista Latinoamericana de psicopatologia fundamental, X(2), 203-218. 
Kristeva, J. (1993). Les Nouvelles Maladies de L’Âme. Paris: Fayard.

Messy, J. (1992). A pessoa idosa não existe. São Paulo: Aleph.

Millot, C. (1988). Nobodaddy, a histeria no século. Rio de Janeiro: Jorge Zahar.

Sawaia, B. B. (2006). Dimensão ético-afetiva do adoecer da classe trabalhadora. In S. T. M. Lane \& B. B. Sawaia (Orgs.). Novas veredas da psicologia social (pp. 157-168). São Paulo: Brasiliense.

Turkle, S. (1985) The Second Self: Computers and the Human Spirit. New York: Simon \& Schuster, Inc.

Vilhena, J. \& Novaes, J. V. (2009). Un corps à la recherche d'un logement. Corps, violence et médecin. In C. Masson \& C. Desprat-Pequignot (Orgs.) Le corps contemporain: créations et faits de culture (pp. 113-136). Paris: L'Harmatan.

Vilhena, J. (2012). Repensando a velhice em tempos sombrios. In R. Pocinho \& E. Santos (Orgs.). Envelhecer em tempos de crise: respostas sociais (pp. 11-28). Coimbra: Legis Editora.

Vilhena, J. et al. (2013). Para além dos anos vividos. Uma leitura das categorias clínicodiscursivas acerca da velhice. In R. Pocinho \& E. Santos (Orgs.). Envelhecer hoje, conceitos e práticas (pp. 151-175). Curitiba: Appris.

\section{Resumos}

(The shadow of a body that presents itself: body image and aging)

Old age has facets and preconceptions that are associated with what it represents. Our aim here is to study the peculiarities related to the phenomenon of being old and its impacts on the subject. We focus on how individuals deal with the disparity between the timeless unconscious and the aged body. We assume that the discourses that standardize the body dominate the symbolic subjective life of the subject and leave no room for the construction of an individual narrative.

Key words: Ageing, body, death, psychoanalysis

(L'ombre d'un corps qui s'annonce: corps, image et vieillir)

La vieillesse possède de nombreuses facettes et de préjugés associés à ce qu'elle représente. Notre article porte sur l'étude des particularités liées au phénomène d'être âgé et de ses impacts sur le sujet, en soulignant comment le décalage entre l'inconscient intemporel et le corps âgé, aussi appelé vieillir, est géré. Nous supposons que les discours qui normalisent le corps dominent la vie symbolique subjective du sujet, ne laissant aucun espace pour la construction d'un récit individuel.

Mots clés: Vieillir, corps, mort, psychanalyse 


\section{ENSAIO}

(Bajo la sombra de un cuerpo que se anuncia: cuerpo, imagen y envejecimiento)

La vejez tiene muchos aspectos y prejuicios asociados a lo que representa. Nuestro objetivo es estudiar lo que es peculiar acerca del fenómeno de 'ser viejo' y sus impactos en el sujeto, destacando el manejo del desacuerdo entre el inconsciente atemporal y el cuerpo envejecido, a que se refiere el envejecimiento. Partimos del supuesto de que los discursos que regulan el cuerpo dominan la vida simbólica y subjetiva del sujeto sin dejar espacio para la construcción de una narrativa individual.

Palabras claves: Envejecimiento, cuerpo, muerte, psicoanálisis

(Der Schatten eines Körpers, der sich ankündigt: Körper, Image und Altern)

Das Alter hat verschiedene Facetten und ist mit Vorurteilen belastet bezüglich dessen, was es darstellt. Unser Ziel ist es, die Besonderheiten in Zusammenhang mit dem Phänomen des alt Seins und seinen Auswirkungen auf das Individuum zu untersuchen, wobei wir hervorheben, wie mit der Diskrepanz zwischen dem zeitlosen Unbewussten und dem gealterten Körper - auch das Altern genannt - umgegangen wird. Wir gehen davon aus, dass die Ansätze, die den Körper in Normen fassen, das symbolischsubjektive Leben des Subjekts bestimmen und folglich kein Raum zur Entwicklung einer individuellen Gestaltung bleibt.

Schlüsselwörter: Altern, Körper, Tod, Psychoanalyse

Citação/Citation: Vilhena, J. de, Novaes, J. de V., \& Rosa, C. M. (2014, junho). A sombra de um corpo que se anuncia: corpo, imagem e envelhecimento. Revista Latinoamericana de Psicopatologia Fundamental, 17(2), 251-264.

Editor do artigo/Editor: Prof. Dr. Manoel Tosta Berlinck

Recebido/Received: 30.4.2013/4.30.2013 Aceito/Accepted: 25.7.2013/7.25.2013

Copyright: (C) 2009 Associação Universitária de Pesquisa em Psicopatologia Fundamental/ University Association for Research in Fundamental Psychopathology. Este é um artigo de livre acesso, que permite uso irrestrito, distribuição e reprodução em qualquer meio, desde que o autor e a fonte sejam citados / This is an open-access article, which permits unrestricted use, distribution, and reproduction in any medium, provided the original author and source are credited. 
Financiamento/Funding: Os autores declaram não ter sido financiadas ou apoiadas / The authors have no support or funding to report.

Conflito de interesses/Conflict of interest: Os autores declaram que não há conflito de interesses / The authors declare that has no conflict of interest.

\section{JUNia de Vilhena}

Psicanalista; Membro efetivo do CPRJ (Rio de Janeiro, RJ, Br); Doutora em Psicologia Clínica; Professora do Programa de Pós-Graduação em Psicologia Clínica da Pontifícia Universidade Católica do Rio de Janeiro - PUC-Rio (Rio de Janeiro, RJ, Br); Coordenadora do Laboratório Interdisciplinar de Pesquisa e Intervenção Social - LIPIS da PUC-Rio; Pesquisadora da Associação Universitária de Pesquisa em Psicopatologia Fundamental (São Paulo, SP, Br); Pesquisadora correspondente do Centre de Recherches Psychanalyse et Médecine, CRPMPandora. Université Denis-Diderot Paris VII (Paris, Fr); Investigadora-Colaboradora do Instituto de Psicologia Cognitiva da Universidade de Coimbra (Coimbra, Portugal).

Av. Ataulfo de Paiva, 135/613 - Leblon

22440-901 Rio de Janeiro, RJ, Br

e-mail: vilhena@puc-rio.br

www.juniadevilhena.com.br

\section{Joana de Vilhena Novaes}

Professora do Programa de Pós-Graduação em Psicanálise, Clínica e Sociedade da Universidade Veiga de Almeida (Rio de Janeiro, RJ, Br); Pós-doutora em Psicologia Médica pela Universidade do Estado do Rio de Janeiro - UERJ (Rio de Janeiro, RJ, Br); Pós-doutora em Psicologia Social pela mesma Universidade; Doutora em Psicologia Clínica pela Pontifícia Universidade Católica do Rio de Janeiro - PUC-Rio (Rio de Janeiro, RJ, Br); Coordenadora do Núcleo de Doenças da Beleza da PUC-Rio; Pesquisadora e psicoterapeuta do LIPIS/ PUC-Rio; Pesquisadora correspondente do Centre de Recherches Psychanalyse et Médecine - Université Denis-Diderot Paris VII CRPM-Pandora (Paris, Fr).

Av. Ataulfo de Paiva, 135/613 - Leblon

22440-901 Rio de Janeiro, RJ, Br

e-mail: joanavnovaes@gmail.com

www.joanadevilhenanovaes.com.br

\section{Carlos Mendes Rosa}

Psicólogo; Doutorando do Programa de Pós-Graduação em Psicologia Clínica da Pontifícia Universidade Católica do Rio de Janeiro - PUC-Rio (Rio de Janeiro, RJ, Br); Mestre em Psicologia pela Pontifícia Universidade Católica do Rio de Janeiro - PUC-Rio (Rio de Janeiro, RJ, Br); Especialização em Psicopatologia Clínica pela UNIP - Universidade Paulista; Pesquisador Associado do LIPIS/PUC-Rio; Professor do IBMR Centro Universitário (Rio de Janeiro, RJ, Br).

Rua Riachuelo, 257/421 - Lapa

20230-011 Rio de Janeiro, RJ, Br

e-mail: carlosmendesrosa@gmail.com 